\title{
EFFECT OF AN INTRA-UTERINE DEVICE ON GAMETE TRANSPORT AND FERTILIZATION IN THE RHESUS MONKEY
}

\author{
J. H. MARSTON,* W. A. KELLY $\dagger$ AND P. EGKSTEIN \\ Department of Anatomy, Medical School, Birmingham 15
}

(Received 5th Fuly 1968)

Summary. In the naturally cyclic rhesus monkey, the presence of an intra-uterine device (IUD) did not obviously disturb the processes of (a) transport of the ovulated egg through the Fallopian tube; (b) transport of spermatozoa through the female genital tract; (c) fertilization, and (d) early embryonic development within the Fallopian tube.

Correlation of observations on egg recovery with those on the morphological age of the corpus luteum suggested that transport of the naturally ovulated egg through the Fallopian tube was completed within 3 to 4 days after ovulation in both the control and IUD monkeys.

Eggs could be recovered from the uteri of control monkeys, but usually not from those of IUD monkeys. It was concluded that the presence of an IUD probably induced pre-implantation destruction of embryos within the uterus of the naturally cyclic rhesus monkey.

\section{INTRODUCTION}

Naturally cyclic rhesus monkeys fitted with an intra-uterine device (IUD) do not become pregnant when they are mated with males of proved fertility. However, the IUD animals show a normal periodicity and duration of menstruation, and ovulation occurs at the normal time in the menstrual cycle (Eckstein, Kelly \& Marston, 1969; Kelly, Marston \& Eckstein, 1969a). It has not yet been absolutely established that an intra-uterine device is contraceptive in the rhesus monkey. The study of Kelly et al. (1969a) could not eliminate the possibility that IUD monkeys conceived and then suffered an early abortion. It is, therefore, necessary to see whether an IUD can prevent implantation.

Mastroianni \& Rosseau (1965) have reported that an IUD caused dramatic acceleration of egg transport through the Fallopian tube of superovulated rhesus monkeys. In a subsequent study (Mastroianni, Suzuki, Manabe \& Watson, 1967), the same effect could not be observed in naturally cyclic rhesus monkeys. This confirmed the observation that an IUD did not disturb the pattern of tubal transport (Kelly \& Marston, 1967).

This paper, the third in this series of communications (Eckstein et al., 1969;

* Present address: Physiological Laboratory, Cambridge CB2 3EG.

+ Present address: Department of Anatomy, The University, Bristol BS8 1TD. 
Kelly et al., 1969a), reports on the effects of an IUD on the tubal transport of the ovulated egg, the transport of spermatozoa, the occurrence of fertilization and the fate of the fertilized egg in naturally cyclic rhesus monkeys.

\section{MATERIALS AND METHODS}

\section{Animals}

Observations were made on mature female rhesus monkeys with an established menstrual periodicity. Full details of their management and preparation have been described by Eckstein et al. (1969).

Female monkeys were mated with selected males of proved fertility. The supervision of these males and the procedure for mating has been described by Kelly et al. (1969a).

\section{Surgical procedures}

All the laparotomies were performed through a mid-ventral incision using an aseptic technique.

Ovariosalpingectomy. Gonventional techniques were used with special care to ligate and excise the Fallopian tube as close as possible to the point where it entered the myometrium.

Irrigation of the Fallopian tube at laparotomy. The techniques described by Hartman (1944) and slightly modified by Mastroianni \& Rosseau (1965) were used.

Irrigation of the uterus at laparotomy. This was done by injecting $5 \mathrm{ml}$ of $0.9 \%$ saline into the uterine lumen whilst the internal os of the cervix was occluded by digital pressure. The saline was drained from the lumen through a small cannula which had previously been inserted into the lumen by piercing the fundus.

\section{Examination of specimens}

Recovery of eggs and spermatozoa. After salpingectomy, eggs and spermatozoa were recovered from the Fallopian tube by flushing with Ringer's solution. At autopsy, the genital tract was removed, and the Fallopian tubes, uterus, cervix and vagina were carefully separated and individually flushed with Ringer's solution. Great care was taken not to contaminate the Fallopian tube and uterus with the contents of the cervix and vagina.

The tubal and uterine flushes were examined under a dissecting microscope, and once eggs had been identified they were examined, fixed and stained as described by Marston \& Chang (1964). The various flushes were then microscopically examined for the presence of spermatozoa by using either aliquots of the total specimen or the sediment after centrifuging the larger specimens. At autopsy, the presence of spermatozoa was also checked by 'imprinting' the epithelial surfaces of the Fallopian tubes and endometria on to microscope slides. These 'imprints' were stained and routinely examined for spermatozoa.

Condition of the ovaries and corpora lutea. At laparotomy, the condition of the ovaries was recorded and in most cases they were photographed. At autopsy, or after ovariosalpingectomy, the ovaries were fixed in aqueous Bouin's solution 
and then submitted for routine histological examination (cf. Kelly et al., 1969a). Serial sections of the ovaries were examined so that the morphological age of the corpora lutea could be estimated according to the criteria of Corner (1945).

\section{RESULTS}

\section{Recovery of eggs}

Table 1 provides an overall summary of the attempts to recover naturally ovulated eggs from the Fallopian tube and uterus of mated rhesus monkeys. The observations were all obtained from animals which had normal genital tracts. The majority of the observations were made at laparotomy by irrigating the uterus and the Fallopian tube, but others were obtained by combining uterine irrigation with unilateral ovariosalpingectomy. Small groups of monkeys were killed on Days 15 and 16 of the menstrual cycle so that the genital

TABLE 1

EFFECT OF AN IUD ON EGG RECOVERY FROM MATED RHESUS MONKEYS EXAMINED ON DAYS 11 TO 19 OF THE MENSTRUAL GYCLE

\begin{tabular}{|c|c|c|c|c|c|c|c|}
\hline & \multirow{2}{*}{$\begin{array}{l}\text { Total no. } \\
\text { monkeys } \\
\text { examined }\end{array}$} & \multicolumn{3}{|c|}{ Ovarian condition } & \multicolumn{2}{|c|}{ Eggs recovered } & \multirow{2}{*}{ Details of fertilized eggs } \\
\hline & & $\begin{array}{c}\text { With } \\
\text { ovulation }\end{array}$ & $\begin{array}{c}\text { Pre- } \\
\text { ovulatory }\end{array}$ & Inactive & Total & Fertilized & \\
\hline Control & $\begin{array}{c}42 \\
\begin{array}{c}74 \text { observa- } \\
\text { tions) }\end{array}\end{array}$ & 56 & 6 & 12 & 22 & 9 & $\begin{array}{l}1 \times \text { Early penetration } \\
1 \times \text { Pro-nuclear } \\
2 \times \text { Two-cell } \\
1 \times \text { Four-cell } \\
1 \times \text { Seven-cell } \\
1 \times \text { Nine-cell } \\
1 \times \text { Eleven-cell } \\
1 \times \text { Forty-cell }\end{array}$ \\
\hline IUD & $\begin{array}{c}35 \\
\begin{array}{c}80 \text { observa- } \\
\text { tions) }\end{array}\end{array}$ & 56 & 15 & 9 & 23 & 8 & $\begin{array}{l}1 \times \text { Early penetration } \\
2 \times \text { Pro-nuclear } \\
1 \times \text { Two-cell } \\
2 \times \text { Four-cell } \\
1 \times \text { Five-cell } \\
1 \times \text { Degenerate morula }\end{array}$ \\
\hline
\end{tabular}

tract could be completely examined for the presence of eggs and spermatozoa. In other cases, monkeys were examined at autopsy at the conclusion of other experiments (Marston \& Kelly, 1968a; Marston, Kelly \& Eckstein, 1969). Table 1 shows that there was no difference in the recovery of eggs from the genital tracts of control and IUD monkeys. There was also no difference between the two groups in the occurrence of fertilization.

More detailed examination of these results showed that eight of the twentytwo eggs from control monkeys were recovered from the uterus, whereas only two of twenty-three eggs were found at this site in IUD monkeys. The difference between these observations was significant $(P<0.025)$ by analysis of chi-square, but could be explained by relating the site of egg recovery to the morphological age of the corpus luteum (Table 2). Table 2 records only those results obtained where an egg had been recovered, or where both the Fallopian tube and the 
uterus had been examined at autopsy: the ovulated ovaries had all been serially sectioned so the morphological age of the corpora lutea could be estimated. A previous investigation (Kelly et al., 1969a) established that there was no difference in the appearance or the development of corpora lutea of similar age recovered from control and IUD monkeys.

Provided the corpus luteum was not more than 3 days old, there was no difference in the recovery of eggs from the Fallopian tubes of control and IUD monkeys. Transport of the egg through the Fallopian tube in naturally cyclic rhesus monkeys was completed within 3 or 4 days of ovulation.

Chi-square analysis showed that there was a significant difference $(P<0.05)$ between the proportion of eggs that could be recovered from the uterus in control and IUD monkeys when the corpus luteum was 4 to 7 days old. Eggs

TABLE 2

EFFECT OF AN IUD ON EGG RECOVERY FROM RHESUS MONKEYS IN RELATION TO THE MORPHOLOGY OF THE GORPUS LUTEUM

\begin{tabular}{|c|c|c|c|c|c|}
\hline & \multirow{4}{*}{$\begin{array}{c}\text { Total no. } \\
\text { observations }\end{array}$} & \multicolumn{4}{|c|}{ Morphological age of corpus luteum (days) } \\
\hline & & 1 & 2 to 3 & \multicolumn{2}{|c|}{4 to 7} \\
\hline & & \multicolumn{4}{|c|}{ Monkeys yielding eggs from: } \\
\hline & & $\begin{array}{c}\text { Fallopian } \\
\text { tube }\end{array}$ & $\begin{array}{c}\text { Fallopian } \\
\text { tube }\end{array}$ & $\begin{array}{c}\text { Fallopian } \\
\text { tube }\end{array}$ & Uterus \\
\hline $\begin{array}{l}\text { Control } \\
\text { IUD }\end{array}$ & $\begin{array}{l}25 \\
23\end{array}$ & $\begin{array}{l}4 / 6^{*} \\
1 / 1\end{array}$ & $\begin{array}{l}4 / 5 \\
5 / 6\end{array}$ & $\begin{array}{l}1 / 14 \dagger \\
0 / 16\end{array}$ & $\begin{array}{l}6 / 14 \\
2 / 16\end{array}$ \\
\hline
\end{tabular}

* Monkeys with eggs/total monkeys examined.

$\uparrow$ This monkey had a stenosed Fallopian tube therefore not included in $\chi^{2}$ analysis.

could be recovered from the uterus in control monkeys up to 7 days after ovulation, as judged by the age of the corpus luteum. In the IUD monkeys, only two eggs were recovered from the uterus and these were associated with 6-day-old corpora lutea. They were found in the course of other experiments which had involved surgical interference within the uterine lumen. Two control monkeys which had received the same treatment also yielded eggs from the uterus (Marston \& Kelly, 1968a). The possibility exists that surgical interference may have been a significant factor in the recovery of the IUD eggs.

\section{Fertilization and embryonic development within the Fallopian tube}

In the control animals, fertilized eggs which had developed beyond the sevencell stage were all recovered from the uterus. In the IUD monkeys, the degenerate morula (Table 1) was recovered from the uterus, and the other stages were developing in the Fallopian tube. Embryonic development within the Fallopian tube of control and IUD monkeys appeared to be entirely normal. The morphology of the present series of fertilized eggs will be described elsewhere (Marston \& Kelly, unpublished data). 
Transport of spermatozoa through the female genital tract

The fact that fertilization was not disturbed in the presence of an IUD established that the processes of sperm-transport were adequate and also that the presence of an IUD could not have interfered with the process of capacitation, if this is necessary in the rhesus monkey (Marston \& Kelly, 1968b).

\section{TABLE 3}

EFFECT OF AN IUD ON THE RECOVERY OF SPERMATOZOA FROM THE UTERUS AND FALLOPIAN TUBES OF RHESUS MONKEYS AT LAPAROTOMY

\begin{tabular}{l|c|c|c|c}
\hline & $\begin{array}{c}\text { Hours after } \\
\text { detection } \\
\text { of motile } \\
\text { spermatozoa } \\
\text { in vagina }\end{array}$ & $\begin{array}{c}\text { Total no. } \\
\text { observations }\end{array}$ & $\begin{array}{c}\text { Spermatozoa recovered } \\
\text { from: }\end{array}$ \\
\cline { 2 - 4 } Control & 0 & 13 & 9 & 1 \\
(21 females) & 24 & 14 & 7 & 1 \\
IUD & 48 & 7 & 2 & 0 \\
(22 females) & 0 & 16 & 11 & 0 \\
& 24 & 7 & 3 & 1 \\
\hline
\end{tabular}

* Does not include spermatozoa recovered in a cumulus clot or embedded in a fertilized egg.

TABLE 4

EFFECT OF AN IUD ON REGOVERY OF SPERMATOZOA FROM THE GENITAL TRACT AT AUTOPSY ON DAY 15 OF THE MENSTRUAL CYGLE

\begin{tabular}{c|c|c|c|c|c}
\hline $\begin{array}{c}\text { Time of } \\
\text { autopsy } \\
\text { (hr } \\
\text { after } \\
\text { mating) }\end{array}$ & Group & \multicolumn{4}{|c}{ Approximate nos. and motility of spermatozoa } \\
\hline & & Vagina & Cervix & Uterus & $\begin{array}{c}\text { Fallopian } \\
\text { tube }\end{array}$ \\
\hline 0 to 4 & Control & $>10^{7}$, motile & $>10^{4}$, motile & $<10^{3}$, motile & about 10, motile \\
& IUD & $>10^{7}$, motile & $>10^{4}$, motile & 0 & 0 \\
16 to 18 & Control & $>10^{7}$, immotile & $>10^{4}$, motile & 0 & 0 \\
& IUD & $>10^{7}$, immotile & $>10^{4}$, motile & $<10^{3}$, immotile & 0 \\
25 to 27 & Control & $>10^{6}$, immotile & $<10^{4}$, motile & 0 & 0 \\
36 to 38 & IUD & $>10^{6}$, immotile & $<10^{4}$, motile & $<10^{3}$, immotile & 0 \\
& Control & $>10^{5}$, immotile & $<10^{4}$, motile & $<10^{3}$, immotile & 0 \\
& IUD & $>10^{5}$, immotile & $<10^{4}$, motile & $<10^{3}$, immotile & 0 \\
\hline
\end{tabular}

During the egg recovery experiments, an attempt was made to see whether spermatozoa could be recovered from the genital tract of the naturally mated rhesus monkey. The results of these routine observations are shown in Table 3.

There was little difference in the recovery of spermatozoa from the control and IUD monkeys. Spermatozoa were more frequently recovered from monkeys that had recently copulated. Isolated spermatozoa were very infrequently found in the Fallopian tube, although fertilized eggs had from nought to seven 
spermatozoa embedded in their zona pellucida. Rarely, as many as $10^{4}$ spermatozoa were found in the uterus, but more frequently $<10^{3}$ spermatozoa were recovered. Motile spermatozoa were usually present in large numbers in the endocervical canal of recently mated monkeys.

More detailed studies were attempted in four control and four IUD monkeys. They were mated with one fertile male (No. 953) for a period of $2 \mathrm{hr}$, and then killed on Day 15 of the menstrual cycle, at varying times after mating. The results are shown in Table 4. All of the monkeys mated with the male and many motile spermatozoa were found in the vagina immediately after mating. These results confirmed the previous observations that few spermatozoa could be recovered from the uterus and Fallopian tubes close to the expected time of ovulation.

\section{DISGUSSION}

The results of this study show that the presence of an IUD does not markedly disturb the pattern of tubal transport in the naturally cyclic rhesus monkey. Fertilized eggs appear to enter the uterus normally, and once in the uterine lumen they undergo rapid degeneration and/or premature expulsion. Other studies have shown that premature expulsion of eggs from the uterus probably does not occur in the presence of an IUD (Marston \& Kelly, 1968a; Marston et al., 1969). Thus, by inference, it appears that fertilized eggs undergo premature degeneration within the uterus of IUD monkeys and it is, therefore, improbable that implantation can occur in the presence of an IUD. It would follow that an IUD does exert a contraceptive effect in the naturally cyclic rhesus monkey.

This action of an IUD may be mediated by alteration of the uterine milieu. Other studies have shown that certain morphological changes are invariably present in the surface epithelium and immediately subjacent stroma of the endometrium in naturally cyclic IUD rhesus monkeys (Kelly, Marston \& Eckstein, 1969b). These morphological changes may be sufficient to produce changes within the uterine milieu.

Mastroianni et al. (1967) could find neither direct nor indirect evidence to suggest that an IUD disturbed tubal transport in naturally cyclic rhesus monkeys. They also noted that spermatozoa could be recovered from the Fallopian tubes of both the control and IUD monkeys after artificial insemination. However, Mastroianni (1967) has emphasized that there is an important difference between the effects exerted by an IUD in naturally cyclic monkeys and in gonadotrophin-stimulated, superovulated animals.

Mastroianni \& Rosseau (1965) found that $5 \mathrm{hr}$ after superovulation, eggs had been ejected from the Fallopian tube of IUD monkeys and could only be recovered from the uterus. In identically treated control monkeys, eggs were only found in the Fallopian tube and could not be recovered from the uterus. They concluded that, in the rhesus monkey, an IUD caused eggs to be rapidly transported through the Fallopian tube. But although it was the crucial reference point for their study, they did not establish exactly when superovulation occurred in their control and IUD monkeys, nor did they complete a series of 
timed studies to compare the rates of tubal transport in the two groups of animals. The enhanced rate of egg-transport in superovulated IUD monkeys might not have been particularly significant for it has been shown that superovulation can induce accelerated tubal transport in farm animals and also in the squirrel monkey (Bennett, 1967).

In additional studies on gonadotrophin-stimulated IUD monkeys, Mastroianni et al. (1967) observed that rabbit eggs passed through the Fallopian tubes within 60 min of being transferred to their ampullae. No significant movement could be detected in identically treated control animals. Again, a series of timed studies was not completed. If a marked acceleration of tubal transport in the presence of an IUD can be demonstrated in gonadotrophin-stimulated monkeys, then the mechanism underlying this action will, indeed, be of great interest (cf. Mastroianni, 1967).

The theory that an IUD disturbs the normal pattern of function within the human Fallopian tube was advanced by Margulies (1962) and Tietze (1962) on the basis of statistical and clinical evidence. The results of Mastroianni \& Rosseau (1965) have been widely and uncritically cited by clinical workers as evidence supporting this theory. Tietze $(1962 ; 1966 \mathrm{a}, \mathrm{b})$ suggested that the unexpected rarity of ectopic pregnancy in IUD patients might provide substantial support for the theory of altered tubal function. This evidence is also consistent with the view that the presence of an IUD helps to eliminate those pathological processes which predispose to ectopic conception, and, on this basis, an IUD need not necessarily affect the physiology of the normal Fallopian tube.

The theory of Margulies and Tietze is not supported by evidence from numerous attempts to recover eggs and spermatozoa from the Fallopian tubes of women subjected to elective salpingectomy at the time of expected ovulation. In a WHO study which included the data of Noyes, Glewe, Bonney, Burrus, DeFeo \& Morgenstern (1966), eleven eggs were recovered from the tubes of ninety-two patients fitted with IUDs, and only twelve from 161 women without IUDs. This difference is not significant on chi-square analysis, and it would appear that the tubal transport of eggs in women is not noticeably affected by the presence of an IUD. One fertilized egg was recovered from that series of IUD patients and four were found in the controls. There is good evidence, however, that spermatozoa can be recovered from the Fallopian tubes of IUD patients as frequently as from controls (Malkani \& Sujan, 1964; Morgenstern, Orgebin-Crist, Clewe, Bonney \& Noyes, 1966). Therefore it is likely that fertilization occurs with normal frequency in IUD patients.

It is possible that, in women, as in the rhesus monkey, an IUD exercises its contraceptive action in the uterus and not in the Fallopian tube. Whether, in fact, this site of action can be established will depend on the results of extensive, well planned, clinical research.

\section{ACKNOWLEDGMENTS}

This work was supported by a grant from the Ford Foundation, New York, whose help we gratefully acknowledge. 
The histological techniques were expertly performed by Miss Margaret Giles, who, with Mr J. Browning, has given us constant assistance. Mr H. Smith, $\mathrm{Mr} \mathrm{F}$. James and $\mathrm{Mr}$ G. Tonks were responsible for the care and supervision of the rhesus monkeys.

\section{REFERENCES}

BenNett, J. P. (1967) Artificial insemination of the squirrel monkey. F. Endocr. 37, 473.

CORNER, G. W. (1945) Development, organisation and breakdown of the corpus luteum in the rhesus monkey. Contr. Embryol. 31, 117.

Eckstein, P., KelLy, W. A. \& Marston, J. H. (1969) Effect of an intra-uterine device on menstrual periodicity in the rhesus monkey. F. Reprod. Fert. 19, 133.

Hartman, C. G. (1944) Recovery of primate eggs and embryos: methods and data on the time of ovulation. West. F. Surg. Obstet. Gynec. 52, 3.

Keliy, W. A. \& Marston, J. H. (1967) Action of intra-uterine devices in rhesus monkeys. Nature, Lond. 214, 735.

Kelly, W. A., Marston, J. H. \& Eckstein, P. (1969a) Effect of an intra-uterine device on conception and ovulation in the rhesus monkey. F. Reprod. Fert. 19, 143.

Kelly, W. A., Marston, J. H. \& Eckstein, P. (1969b) Effect of an intra-uterine device on endometrial morphology and the deciduomal reaction in the rhesus monkey. F. Reprod. Fert. 19, 331.

Malkani, P. K. \& Sujan, S. (1964) Sperm migration in the female reproductive tract in the presence of intra-uterine devices. Am. F. Obstet. Gynec. 88, 963.

Margulies, L. C. (1962) Permanent reversible contraception with an intra-uterine plastic spiral. Proc. Conf. IUCD, New York. Excerpta med. int. Congr. Ser. No. 54, 61.

Marston, J. H. \& Chang, M. C. (1964) The fertilizable life of ova and their morphology following delayed insemination in mature and immature mice. F. exp. Zool. 155, 237.

Marston, J. H. \& Kelly, W. A. (1968a) Effect of an intra-uterine device on uterine motility in the rhesus monkey. Nature, Lond. 217, 774.

Marston, J. H. \& Kelly, W. A. (1968b) Time relationships of spermatozoon penetration into the egg of the rhesus monkey. Nature, Lond. 217, 1073.

Marston, J. H., Kelly, W. A. \& Eckstein, P. (1969) Effect of an intra-uterine device on uterine motility in the rhesus monkey. F. Reprod. Fert. 19, 321.

Mastroianni, L. (1967) Contraceptive action of intra-uterine devices in the rhesus monkey. Nature, Lond. 215, 1172.

Mastroianni, L. \& RosseaU, G. H. (1965) Influence of intra-uterine coil on ovum transport and sperm distribution in the monkey. Am. 7. Obstet. Gynec. 93, 416.

Mastroianni, L., Suzuki, S., Manabe, Y. \& Watson, F. (1967) Further observations on the influence of the intra-uterine device on ovum and sperm distribution in the monkey. Am. F. Obstet. Gynec. $99,649$.

Morgenstern, L. L., Orgebin-Grist, M. C., Glewe, T. H., Bonney, W. A. \& Noyes, R. W. (1966) Observations on spermatozoa in the human uterus and oviducts in the chronic presence of intra-uterine devices. Am. 7. Obstet. Gynec. 96, 114.

Noyes, R. W., Ceewe, T. H., Bonney, W. A., Burrus, S. B., Defeo, V. J. \& Morgenstern, L. L. (1966) Searches for ova in the human uterus and tubes. (1) Review, clinical methodology and summary of findings. Am. F. Obstet. Gynec. 96, 157.

TiETzE, G. (1962) Intra-uterine contraceptive rings: history and statistical appraisal. Proc. Conf. IUCD, New York, Excerpta med. int. Congr. Ser. No. 54, 9.

TIETze, C. (1966a). Extra-uterine pregnancy and intra-uterine devices. Br. med. F. ii, 302.

TIETZE, C. (1966b) Contraception with intrauterine devices. Am. F. Obstet. Gynec. 96, 1043.

WHO (1966) Intra-uterine devices: physiological and clinical aspects. Wld Hlth Org. No. 39. 